\title{
Vaccinations in Patients Receiving Systemic Drugs for Skin Disorders: What Can We Learn for SARS-Cov-2 Vaccination Strategies?
}

\author{
Reinhart Speeckaert ${ }^{1}$ (D) Jo Lambert ${ }^{1} \cdot$ Luis Puig $^{2} \cdot$ Marijn Speeckaert $^{3} \cdot$ Hilde Lapeere $^{1} \cdot$ Sofie De Schepper $^{1}$. \\ Nanja van Geel ${ }^{1}$
}

Accepted: 14 May 2021 / Published online: 9 June 2021

(c) The Author(s) 2021

\begin{abstract}
Large-scale vaccination strategies are currently being deployed against severe acute respiratory syndrome coronavirus-2 (SARS-Cov-2). Whether systemic medication for skin diseases affects the efficacy of vaccination and whether temporary interruption or extension of the dosing interval is necessary is under debate. Most immunomodulating/immunosuppressive drugs only affect vaccine-induced immune responses to a limited or moderate extent, preserving sufficient immunity in most patients. Mycophenolate mofetil, Janus kinase inhibitors, and rituximab require a more cautious approach, and judicious timing of vaccination might be appropriate in patients receiving these treatments. It should be noted that, for most drugs except methotrexate, data on the length of the interruption period to restore vaccine-induced immune responses to normal levels are either very limited or absent. In these cases, only the drug half-life can be used as a practical guideline. In most patients, systemic medication can be continued through the vaccination process, although case-by-case decisions can be considered.
\end{abstract}

\section{Key Points}

For most patients receiving immune-based treatments for inflammatory skin disorders, the therapy can be continued without affecting protective vaccine-induced immunity.

For some drugs, temporary treatment interruption or administration of the vaccine at the optimal period according to the pharmacokinetics of the drug and the individual level of disease control can be considered.

Reinhart Speeckaert

Reinhart.Speeckaert@uzgent.be

1 Department of Dermatology, Ghent University Hospital, Corneel Heymanslaan 10, 9000 Ghent, Belgium

2 Department of Dermatology, Hospital de la Santa Creu i Sant Pau, Universitat Autònoma de Barcelona, Barcelona, Spain

3 Department of Nephrology, Ghent University Hospital, Ghent, Belgium

\section{Introduction}

In recent decades, the number of systemic medications available for skin disorders has increased. Given the inflammatory nature of most dermatologic disorders, the majority of treatments act by influencing different parts of the immune system. Despite initial concerns, most systemic treatments in dermatology appear to carry a limited risk for severe coronavirus disease 2019 (COVID-19) infections. Some medications have even been proposed as useful in the treatment of the cytokine storm associated with COVID-19. Cyclosporine inhibits replication of different coronaviruses in vitro [1]. Data do not suggest an increased susceptibility to infection or severe disease course in patients treated with biologics [2]. Interestingly, epidermal cells express the angiotensinconverting enzyme receptor (ACE)-2, which acts as an entry receptor for SARS-CoV-2, indicating that the skin could be an entry site for SARS-CoV-2 infection in case of barrier dysfunction. As such, appropriate treatment of skin diseases with impaired integrity of the skin such as eczema may be protective [3].

While some systemic drugs in dermatology are termed immunomodulatory and others immunosuppressive, the question remains as to whether the response to severe acute respiratory syndrome coronavirus-2 (SARS-CoV-2) vaccination will be hampered by these treatments. This is a valuable 
question, as the benefits of temporary interruption of the treatment may outweigh the risks, given that long-lasting irreversible damage is not expected for the most common skin diseases such as psoriasis, eczema, or urticaria. In this paper, we summarize the evidence of the effects of systemic immune-based interventions for skin disorders on vaccine responses and discuss the implications for SARS-CoV-2 vaccination.

\section{Types of COVID Vaccines and Assessment of Efficacy}

SARS-CoV-2 is a member of the betacoronavirus genus, a family of RNA viruses that induce respiratory tract infections. It is the seventh type that can infect humans and the third (besides severe acute respiratory syndrome and the Middle East respiratory syndrome) to be associated with severe disease. Although controversy remains about its origin, the approximately $96 \%$ sequence homology with the RaTG13 virus found in bats suggests a plausible site of origin in zoonotic transmission [4]. SARS-CoV-2 is composed of four main structural proteins: the spike (S) glycoprotein, a small envelope glycoprotein, a membrane glycoprotein, and a nucleocapsid protein, with several additional accessory proteins [5]. The $\mathrm{S}$ protein binds to the ACE2 receptor on the host cell via the $\mathrm{S} 1$ subunit. After a cleavage process, the S2 subunit inserts into the host membrane [6].

Different strategies are being used to develop vaccines against SARS-CoV-2: RNA and DNA vaccines, replicating and nonreplicating viral vectors, inactivated vaccines, live attenuated vaccines, protein subunit vaccines, and virus-like particle vaccines.

RNA vaccines are a new approach to the vaccine arsenal (Fig. 1). Via intramuscular injection of RNA encapsulated in lipid nanoparticles to improve cell delivery, host cells encode proteins that induce a B- and T-cell response. The BioNTech SE/Pfizer vaccine contains the messenger RNA (mRNA) for the S glycoprotein. Similarly, the Moderna vaccine also contains mRNA encoding for the $\mathrm{S}$ protein in the stabilized prefusion form [6].

Self-amplifying RNA vaccines are genetically engineered amplicons that contain the mRNA coding for the desired antigen plus mRNA encoding an RNA-dependent RNA polymerase complex that amplifies synthetic transcripts in situ [7]. One such vaccine by the Imperial College London is currently in phase I of clinical development [8].

The replicating vectors are based on attenuated viruses or specialized strains of viruses developed for vaccination purposes. These vectors harbor a gene that encodes for a viral protein, which is most frequently the $\mathrm{S}$ protein. Replicating vectors will invade host cells, which will lead to the production of the viral antigen and generation of more vectors.

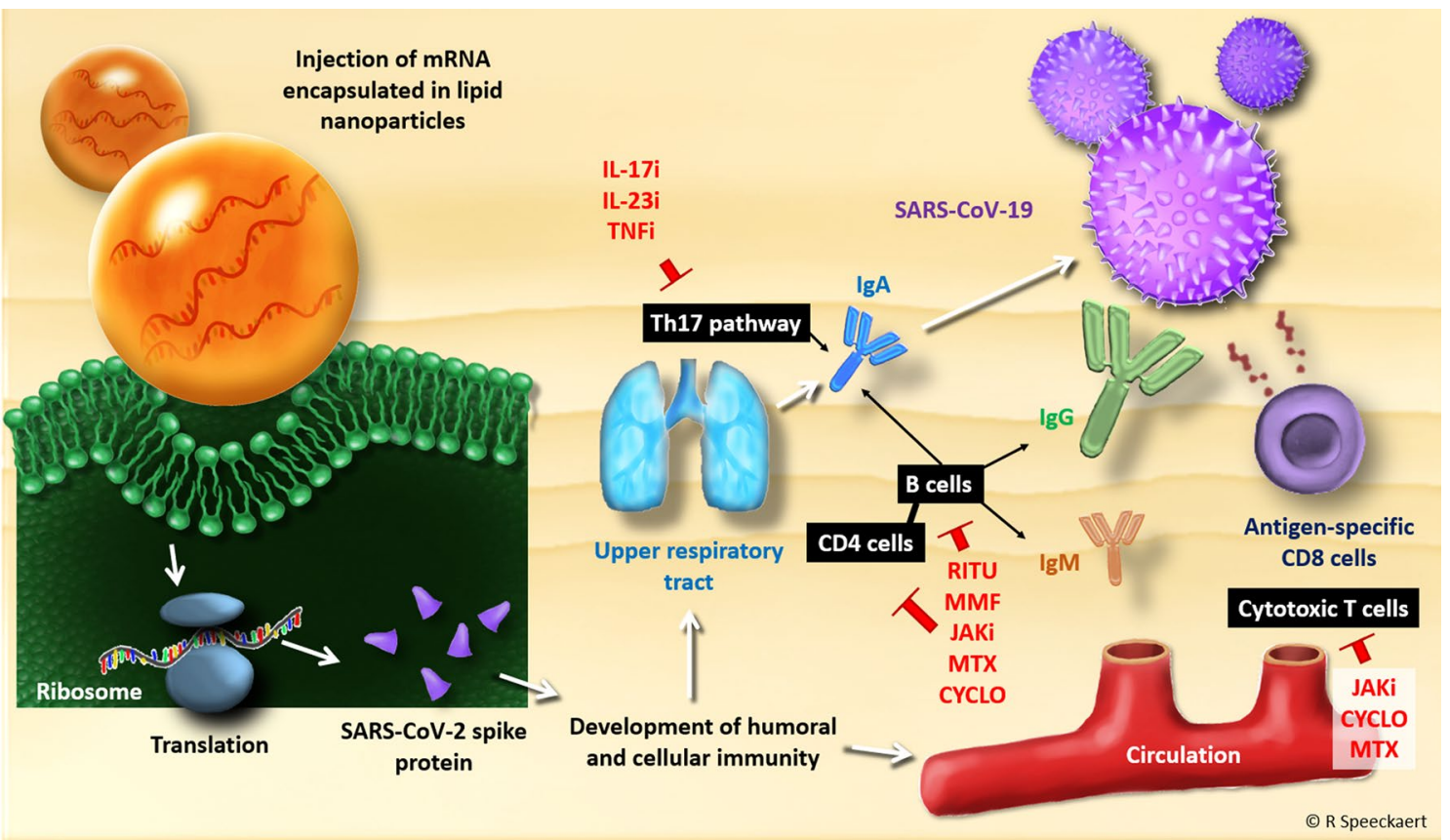

Fig. 1 Working mechanism of mRNA-based vaccines for SARSCoV-2 and the main pathways where immunosuppressive/immunomodulating treatments interact. $C D$ cluster of differentiation, CYCLO cyclosporin, $I L-17 i$ interleukin-17-inhibitors or receptor blockers, $I L-23 i$ interleukin-23 inhibitors, JAKi JAK inhibitors, $M M F$ mycophenolate mofetil, $m R N A$ messenger RNA, MTX methotrexate, $R I T U$ rituximab, SARS-CoV-2 severe acute respiratory syndrome coronavirus-2, Th17 Type 17 T-helper cell 
These will subsequently infect additional cells and amplify the amount of viral antigen, leading to a robust humoral and cellular response. Both replicating and nonreplicating viral vectors are in development, and some have already been approved. The AstraZeneca/University of Oxford and Russian Sputnik V vaccines are based on nonreplicating viral vectors. The Janssen Pharmaceuticals vaccine uses a recombinant adenovirus. For all these vaccines, the SARS-CoV-2 spike gene is inserted into the vector.

Inactivated vaccines are made by inoculation of (in most cases) mammalian Vero cells, followed by chemical inactivation. Live attenuated vaccines have previously been shown to be an effective approach for numerous infections, including measles, mumps, rubella, varicella, tuberculosis, yellow fever, and influenza. The route of administration is important, as intramuscular injections only elicit a strong immunoglobulin (Ig)-G humoral immunity without leading to an increased IgA production in the respiratory tract or mucosal surfaces [9]. Intranasal delivery offers particular protection of the entry point of SARS-CoV-2, the upper respiratory tract. Protein subunit vaccines are the most popular approach in terms of developed vaccines. In contrast to RNA-based vaccines, which require the host cells to produce the antigen, protein subunit vaccines consist of synthetic peptides or recombinant proteins. The most obvious choice is again the $\mathrm{S}$ protein, as the induction of neutralizing antibodies is likely to prevent infection. Virus-like particles are another strategy and involve the administration of nonreplicating, noninfectious nanostructures that expose crucial viral proteins. Finally, DNA vaccines use plasmids encoding for the S protein. Although these types of vaccines are used in animals, the theoretical possibility of the DNA plasmid integrating into the host genome raises some concerns [10].

The primary goal of efficient vaccination is to induce a neutralizing humoral response preventing the virus from invading host cells. IgG antibodies are considered the most important, especially the IgG1 and IgG3 classes, as they offer the most protection. Nonetheless, as mucosal surfaces and both epithelial and endothelial cells in the respiratory tract are identified as cellular targets, the generation of sufficient IgA antibodies may also represent an important protective barrier. Serum IgA dominates the early neutralizing antibody response to SARS-Cov-2, and dimeric IgA, the primary form of antibody in the nasopharynx and other mucosae, is on average 15 times more potent. Intramuscular administration of vaccines is unlikely to elicit significant divalent IgA response in the mucosae, as opposed to intranasal administration, which can result in both $\operatorname{IgA}$ and $\operatorname{IgG}$ responses such as intended for the attenuated COVI-VAC vaccine (NCT04619628) [11-13].

To produce a robust antibody response, both $\mathrm{B}$ cells and cluster of differentiation (CD)- $4^{+}$T-helper cells must be stimulated. $\mathrm{CD} 8^{+}$cytotoxic $\mathrm{T}$ cells are less essential for prevention but crucial to attack virally infected cells. To create a $\mathrm{CD} 8^{+}$-specific immunity, the antigen should be presented via human leukocyte antigen molecules by antigen-presenting cells and/or infected cells. In general, vaccination strategies induce a modest long-term $\mathrm{T}$-cell response, especially when compared with vaccine-induced humoral immunity. For preventive purposes, this might be acceptable as $\mathrm{CD}^{+}$lymphocytes play their primary role after the host cells are infected [10].

\section{Efficacy of Vaccinations during Systemic Treatment}

\subsection{Methotrexate}

Methotrexate is an antimetabolite and antifolate drug that is used in many autoimmune skin disorders because of its anti-inflammatory effects (including inhibition of T-cell proliferation). Substantial evidence shows that methotrexate decreases the efficacy of vaccination. Vaccine responses (e.g., at least fourfold increase in antibody titer after vaccination compared with baseline) to influenza are decreased by 15-20\% [14, 15]. Stopping methotrexate 2 weeks before and 2 weeks after or for 4 weeks postvaccination largely reverses this phenomenon [15]. Another study found no difference regardless of the timing of the last dose of methotrexate if patients stopped methotrexate for 2 weeks after vaccination. This short stop period was sufficient to restore the humoral immunity despite the slow working mechanism of this drug in many inflammatory diseases [14]. Stopping treatment for longer periods (e.g., 4 weeks) induces the risk of disease flares [15].

\subsection{Cyclosporine}

The calcineurin inhibitor cyclosporine decreases T- and B-cell proliferation by reducing interleukin (IL)-2 production. This conventional immunosuppressant diminishes antibody titers after vaccination. Studies have mainly been conducted in transplant patients and have revealed decreased immunologic responses after vaccination for influenza, tetanus, and hepatitis B $[16,17]$. In most studies, the administration of cyclosporine seems to be not associated with a reduced immune response to influenza vaccination compared with other immunosuppressants [18]. Nonetheless, in lung transplant patients, antibody responses were borderline significantly decreased in the cyclosporine versus the tacrolimus group [19]. In renal transplant patients, cyclosporine was associated with impaired immune responses to influenza vaccination, in contrast to azathioprine [17]. Cyclosporine has a relatively short half-life of $18 \mathrm{~h}$. No data are available 
on how long cyclosporine needs to be stopped for optimal responses to vaccination.

\subsection{Mycophenolate Mofetil}

By selectively inhibiting inosine 5'-monophosphate dehydrogenase, a crucial enzyme in purine synthesis, mycophenolate mofetil (MMF) decreases lymphocyte proliferation. MMF is one of the strongest inhibitors of postvaccination humoral immunity. This may not be surprising, as MMF is particularly useful in blistering skin disorders as it reduces pathogenic antibody formation. Significantly reduced antibody titers were confirmed in patients receiving MMF after pneumococcus and influenza vaccination $[18,20]$. MMF has a half-life of 15.7-17.9 h [21]. No trials have investigated how long MMF should be discontinued to prevent a dampened vaccine immunity.

\subsection{Corticosteroids}

Data in elderly patients receiving corticosteroids confirmed sufficient serum antibody responses following influenza vaccination [22, 23] Also, children who took prednisone for an acute asthma exacerbation were able to mount a humoral response similar to that in healthy controls [24]. Likewise, nephrotic children on high-dose prednisone had an antibody response comparable to that in controls [25]. In contrast, a study in asthma revealed an attenuated response to influenza B antigen in subjects on high-dose inhaled steroids [26]. Varicella zoster vaccination was also successful in patients on chronic/maintenance corticosteroids [27].

\subsection{Dimethyl Fumarate}

Fumaric acid esters are used for moderate to severe psoriasis and decrease lymphocyte counts, although its working mechanism has not been fully elucidated. Findings for dimethyl fumarate are reassuring: most patients receiving dimethyl fumarate mount responses against tetanus-diphtheria toxoid, pneumococcal, and meningococcal vaccine [28].

\subsection{Apremilast}

Apremilast, a selective phosphodiesterase-4 inhibitor, reduces the production of proinflammatory cytokines and is registered for psoriasis. No data are available on this drug following vaccination. Given the limited immunosuppressive properties of apremilast, vaccination is likely to be effective and no different than in the general population. Apremilast does not affect B-/T-cell proliferation or the production of immunoglobulins [29].

\subsection{Azathioprine}

Azathioprine has immunosuppressive effects as it inhibits purine metabolism, resulting in decreased lymphocyte proliferation. Anti-hepatitis b surface antigen (anti-Hbs) titers were decreased in patients with inflammatory bowel disease receiving azathioprine (anti-HBs > $10 \mathrm{UI} / \mathrm{L}: 55 \%$ in the azathioprine group vs. $88 \%$ in controls) [30]. One study found that azathioprine did not affect the response to pneumococcal vaccination [31], whereas another detected an impaired antibody response for one of the 12 serotypes after pneumococcal polysaccharide vaccine-23 (PPSV-23) compared with controls [32]. Anti-influenza vaccination evoked antibody responses similar to those in healthy controls in kidney transplant recipients and patients with inflammatory bowel disease on azathioprine. Most findings suggest that azathioprine has a better vaccine-induced immunity profile than MMF and cyclosporine [17, 33].

\subsection{Janus Kinase Inhibitors}

Janus kinase (JAK) blockers reduce different cytokines and signaling of growth factor receptors depending on the type of JAK inhibition (JAK1, JAK2, JAK3, or tyrosine kinase-2). The JAK1/3 inhibitor tofacitinib has major effects on naïve B-lymphocyte development. This suggests a lost ability to raise immunologic protection against novel antigens [34]. Diminished responsiveness to PPSV-23 (tofacitinib: $45.1 \%$ vs. healthy controls: $68.4 \%$ ) was found, especially in patients concomitantly receiving methotrexate. In contrast, results for influenza were reassuring. Temporary drug interruption for 2 weeks ( 1 week before and 1 week after vaccination) did not restore the vaccine's effectiveness [34]. Nonetheless, most patients with psoriasis treated with tofacitinib mounted adequate immunity against pneumococcal infection (after pneumococcal conjugate vaccine-13) and tetanus [35]. PCV-13 vaccination was successful in $68 \%$ of patients with rheumatoid arthritis treated with the JAK1/2 inhibitor baricitinib, whereas only $43 \%$ achieved an at least fourfold increase in antitetanus IgG concentrations. However, most patients in this study were also taking methotrexate $(89 \%)$ and/or corticosteroids (30\%) [36]. Similar results were found for the JAK1 inhibitor upadacitinib, with a satisfactory humoral response (at least twofold increase in antibody levels compared with baseline) to PCV-13 at 12 weeks in $65 \%$ and $55 \%$ of patients for $15 \mathrm{mg}$ and $30 \mathrm{mg}$ upadacitinib, respectively [37]. No data were found for the JAK $1 / 2$ inhibitor ruxolitinib.

\subsection{Biologics}

\subsubsection{Tumor Necrosis Factor-a Blockers}

Tumor necrosis factor (TNF)- $\alpha$ blockers seem to modestly impair the serological response to influenza vaccination 
in patients with spondyloarthritis (anti-TNF $\alpha$ : $51.6 \%$ vs. healthy controls: $74.3 \% ; P=0.002$ ) [38]. In patients with rheumatoid arthritis, one study mentioned that this effect was more pronounced than with methotrexate [39]. In contrast, another report showed the opposite, with normal responses in anti-TNFo-treated patients and decreased results in methotrexate-treated patients [40]. There is an overall consensus that immune responses are lesser in patients receiving anti-TNF $\alpha$ treatment after influenza vaccination, although enough protective immunity is usually reached. The halflife of anti-TNF $\alpha$ agents is relatively long (e.g., 14 days for adalimumab, 20 days for certolizumab pegol) but shorter for etanercept (4 days). Except for etanercept, which can be interrupted without marked reduction in efficacy after restart and is quickly eliminated from the circulation, interruption of TNF $\alpha$-specific biologics for vaccination is more challenging. Longer injection intervals and start/stop strategies might lead to increased antidrug antibodies and reduced long-term efficacy [41]. Moreover, it is unclear which critical threshold of dosing is required to level the vaccination responses to those in healthy controls.

\subsubsection{Interleukin (IL)-17 Inhibitors and IL-17 Receptor Blocker}

Secukinumab does not affect the humoral response to influenza or meningococcal vaccine [42-44]. Similar reassuring data have been reported for tetanus and pneumococcal vaccination for ixekizumab [45]. Secukinumab has a half-life of 27 days, ixekizumab 13 days, brodalumab 10.9 days, and bimekizumab 17-26 days [46-49]. No reports have been published on brodalumab and bimekizumab.

\subsubsection{IL-23 Inhibitors}

The IL-12/-23 inhibitor ustekinumab does not impair the immunogenicity of influenza, pneumococcus, and tetanus vaccination [50, 51]. No data have been published regarding guselkumab, risankizumab, or tildrakizumab, although similar results are to be expected. Ustekinumab has a halflife of 20-39 days, guselkumab 12-19 days, risankizumab 28 days, and tildrakizumab 23 days [52-55].

\subsubsection{Dupilumab}

The IL-4/-13 inhibitor dupilumab did not affect immunity in patients with eczema after tetanus and meningococcal vaccines [56]. Interestingly, transient inhibition of IL-4 and IL-13 using the decoy receptor IL-13R $\alpha 2$ is being explored as a vaccine strategy to enhance mucosal and systemic immunity. IL-4 and IL-13 negatively modulate $\mathrm{CD} 8^{+}$T-cell avidity [57].

\subsubsection{Omalizumab}

No data are available on the anti-IgE antibody omalizumab. Reduced efficacy of vaccination is not expected as IgE antibodies play no role in developing protective vaccine-induced humoral responses.

\subsubsection{Rituximab}

As rituximab specifically targets $\mathrm{CD} 20^{+} \mathrm{B}$ cells, it may inhibit protective vaccine-induced immunity. CD20 is not expressed on early precursor pro-B cells and long-lived plasma cells. Therefore, preexisting antibody titers are largely unaffected. Vaccination responses and the formation of neutralizing antibodies are expected to be blunted until naïve B cells reappear [58]. Decreased levels of seroconversion and reduced titers to pneumococcal, tetanus, and influenza vaccines have been confirmed. The response partially recuperates but is still impaired 6-10 months after infusion [59]. Inactivated herpes zoster vaccine can induce a T-cell response [60]. This might be important for vaccination as $\mathrm{CD}^{+} \mathrm{T}$-cell responses have been confirmed to be crucial for protective immunity against SARS-CoV-2 [61, 62].

\section{Discussion}

Several systemic treatments for skin disorders have been linked to reduced vaccine-induced protective immunity. Given the reversible damage caused by most inflammatory skin diseases, a temporary interruption might be considered for some patients in the context of SARS-CoV-2 vaccination (Table 1). Especially in patients with adequate disease control, holding treatment for a limited time period causes limited harm. The most data are available for methotrexate, where clinical studies have shown that a 2-week interruption after influenza vaccination is sufficient to reverse vaccineinduced immunity to normal levels.

Data for other drugs such as cyclosporine and corticosteroids are more limited, although their short half-life suggests that a similar strategy might work. Nonetheless, most patients receiving corticosteroids or cyclosporine are able to develop sufficient responses without discontinuation. MMF severely affects antibody formation, and temporary treatment adaptation might be considered if possible, although no strong evidence for the correct timing before or after vaccination is available. For TNF blockers (excluding etanercept), the moderately reduced efficacy of vaccination might not outweigh the risk of reduced long-term efficacy because of the small increased risk for the development of antidrug antibodies. The available data indicate that vaccine-induced immunity is not decreased in patients receiving IL-17 or IL-23 inhibitors. A largely uninvestigated 
Table 1 Efficacy and practical information for systemic medication regarding SARS-Cov-2 vaccination for skin disorders

\begin{tabular}{|c|c|c|c|c|}
\hline Drug & Half-life & $\begin{array}{l}94 \% \text { elimination } \\
(4 \times \text { half-life })\end{array}$ & $\begin{array}{l}\text { Reduced efficacy } \\
\text { of vaccination }\end{array}$ & What can we say to our patients? \\
\hline Methotrexate & $3-15 \mathrm{~h}$ & $12-60 \mathrm{~h}$ & Mild-moderate & $\begin{array}{l}\text { Vaccine-induced immunity is decreased but expected to be sufficient in most } \\
\text { patients }[14,15] \\
\text { Stopping treatment for } 2 \text { weeks after vaccination has successfully increased the } \\
\text { efficacy of influenza vaccination }[14]\end{array}$ \\
\hline Cyclosporine & $18 \mathrm{~h}$ & $72 \mathrm{~h}$ & Mild-moderate & $\begin{array}{l}\text { Vaccine-induced immunity is decreased but expected to be sufficient in most } \\
\text { patients [16-18] } \\
\text { Cyclosporine has a short half-life. Temporary interruption (e.g., stop } 3 \text { days } \\
\text { before vaccination and } \geq 2 \text { weeks after vaccination) might increase the effi- } \\
\text { cacy of vaccination, but RWE is lacking }\end{array}$ \\
\hline Mycophenolate mofetil & $15-18 \mathrm{~h}$ & $60-72 \mathrm{~h}$ & Moderate-severe & $\begin{array}{l}\text { Decreased antibody titers after vaccination are likely }[18,20] \\
\text { Temporary interruption (e.g., stop } 3 \text { days before vaccination and } \geq 2 \text { weeks } \\
\text { after vaccination) might increase the efficacy of vaccination, but RWE is } \\
\text { lacking }\end{array}$ \\
\hline Corticosteroids & $2-4 \mathrm{~h}$ & $8-16 \mathrm{~h}$ & Mild & Vaccination responses are adequate in most patients [22-24] \\
\hline Dimethyl fumarate & $1 \mathrm{~h}$ & $4 \mathrm{~h}$ & No-mild & Vaccination responses are adequate in most patients [28] \\
\hline Apremilast & $6-9 \mathrm{~h}$ & $24-36 \mathrm{~h}$ & Unknown & No data are available, but normal responses are expected \\
\hline Azathioprine & $3-5 \mathrm{~h}$ & $12-20 \mathrm{~h}$ & Mild & Vaccination responses are adequate in most patients $[17,32,33]$ \\
\hline $\begin{array}{l}\text { JAK inhibitors } \\
\text { (tofacitinib; baricitinib) }\end{array}$ & $3 \mathrm{~h} ; 12.5 \mathrm{~h}$ & $12 \mathrm{~h} ; 50 \mathrm{~h}$ & Severe & $\begin{array}{l}\text { Diminished responses have been reported, but most patients can still mount } \\
\text { sufficient immunity [34-37] } \\
\text { A 2-week interruption ( } 1 \text { week before and } 1 \text { week after vaccination) seems inef- } \\
\text { fective for reversing the decreased vaccine responses [34]. Therefore, a mini- } \\
\text { mum treatment-free period of } \geq 2 \text { weeks after vaccination could be necessary } \\
\text { for optimal antiviral immunity. However, this is not substantiated by RWE }\end{array}$ \\
\hline TNF- $\alpha$ blockers & $4-20 \mathrm{~d}$ & $16-80 \mathrm{~d}$ & Mild-moderate & $\begin{array}{l}\text { Modestly impaired immunity after vaccination [38-41] } \\
\text { Longer intervals and starting/stopping can cause reduced long-term efficacy, } \\
\text { except for etanercept, which also has a short half-life } \\
\text { Administration of vaccine midcycle or } 2 \text { weeks before the next dosage might be } \\
\text { considered }\end{array}$ \\
\hline $\begin{array}{l}\text { IL-17 inhibitors, IL-17 } \\
\text { receptor blocker }\end{array}$ & $11-27 \mathrm{~d}$ & $44-108 \mathrm{~d}$ & No & $\begin{array}{l}\text { Currently available vaccines (influenza, meningococcus) have excellent efficacy } \\
\text { (only based on data for secukinumab and ixekizumab) [42-45] } \\
\text { It is unclear whether the vaccine-induced protection (IgA) in the upper airways } \\
\text { will be as effective as in healthy controls } \\
\text { Ixekizumab and brodalumab have a moderately short half-life (13 and } 11 \text { days, } \\
\text { respectively) } \\
\text { No evidence is available about whether temporary interruption seems reason- } \\
\text { able }\end{array}$ \\
\hline IL-23 inhibitors & $12-39 \mathrm{~d}$ & $48-156 \mathrm{~d}$ & No & $\begin{array}{l}\text { Currently available vaccines (influenza, tetanus, meningococcus, pneumococ- } \\
\text { cus) have excellent efficacy (based only on data for ustekinumab) [50,51] } \\
\text { It is unclear whether the vaccine-induced protection (IgA) in the upper airways } \\
\text { will be as effective as in healthy controls } \\
\text { Long half-life } \\
\text { No evidence is available as to whether temporary interruption seems reasonable } \\
\text { in real life }\end{array}$ \\
\hline Dupilumab & NR & NR & No & $\begin{array}{l}\text { Data suggest that COVID vaccination will be as effective as in normal individu- } \\
\text { als [56] }\end{array}$ \\
\hline Omalizumab & NR & NR & Unknown & $\begin{array}{l}\text { No published data } \\
\text { No signals that vaccination is affected }\end{array}$ \\
\hline Rituximab $^{\mathrm{a}}$ & NR & NR & Severe & $\begin{array}{l}\text { Protective antibody formation is severely impaired [59] } \\
\text { Cell-specific immunity is likely largely preserved } \\
\text { Given the partial recuperation of B cells after 6-10 months, this time period is } \\
\text { preferable for vaccination }\end{array}$ \\
\hline
\end{tabular}

COVID coronavirus disease 2019, $d$ days, IgA immunoglobulin A, $I L$ interleukin, JAK Janus kinase, NR not relevant (the drug does not decrease the efficacy of vaccination), $R W E$ real-world evidence, $T N F$ tumor necrosis factor

${ }^{a}$ The drug half-life of rituximab does not represent the duration of its immunologic effect 
topic is the theoretical decrease in IgA responses. IL-17A acts as a defense line for outside body barriers, including the respiratory tract and mucosae, by influencing $\operatorname{IgA}$ antibody formation. In mice, subcutaneous priming with a recombinant antigen in a Th17-inducing adjuvant followed by airway boosting promotes high and sustained levels of dimeric $\operatorname{IgA}$ in the lungs, which are dependent on Th17 cells and deficient if IL-17A is depleted [63]. Systemic vaccination is unlikely to elicit significant divalent $\operatorname{IgA}$ responses in the upper respiratory tract, unlike mucosal (e.g., intranasal) vaccination. Additionally, the influence of blocking IL-17 or IL-23 on the protective upper inflammatory tract responses after mucosal vaccination remains to be elucidated.

In patients receiving rituximab, the timing of vaccination beyond 6 months after the last infusion leads to improved outcomes. JAK inhibitors decrease vaccination results. Evidence of how long this treatment should be interrupted to reach the efficacy seen in healthy controls is lacking, except that it is likely to be longer than 2 weeks. Anti-IL-4, antiIL-13, or anti-IgE are unlikely to interfere with proper vaccination responses. Other drugs used in dermatology for their immunomodulating effects, such as dapsone, hydroxychloroquine, and antibiotics (e.g., tetracyclines), have limited data and/or are not expected to interfere with vaccination [64].

How long immunomodulating/immunosuppressive drugs should be stopped before and after vaccination is controversial. For live vaccines, biological agents or disease-modifying drugs should not be started until after 5 half-lives after administration (high-dose corticosteroids: 4 weeks; etanercept: 4 weeks; TNF $\alpha$ inhibitors: 3 months; methotrexate $\geq 20$ mg/week: 4 weeks; and rituximab: 6-12 months) [65]. None of the currently authorized COVID-19 vaccines contain live virus particles. For nonlive vaccines, this period is less clearly defined as most recommendations state that treatment should be continued in patients with immune-mediated conditions [21]. As this also applies for COVID-19 vaccines, most national guidelines on SARS-CoV-2 vaccination agree that treatment should be continued [66, 67]. In general, after 4-5 half-lives, 94-97\% of a drug will be eliminated, which is believed to lie below clinically relevant concentrations [68]. Humoral responses for primary vaccinations begin with the production of specific low-affinity IgM antibodies after a lag phase usually within the first week after vaccination. Higher affinity and avidity IgG antibodies can be detected after 10-14 days, with maximum titers taking up to 4-6 weeks [21]. A minimum period of 2 weeks, up to 4 weeks, is generally recommended before (re-)initiation of the immunosuppressive/immunomodulatory treatment [69]. For drugs given in dosage intervals of $\geq 4$ weeks, administration of vaccines midcycle or 2 weeks before the next dose seems a reasonable option [21]. It should be noted that the data on influenza, pneumococcal, meningococcal, and tetanus vaccination may not be directly generalizable to SARS-CoV-2 vaccines because of differences in the types of vaccination. The classic influenza vaccines are inactivated, mostly splitvirus or subunit vaccines, and some contain live attenuated influenza virus (e.g., nasal spray vaccines). Pneumococcal vaccines (PCV 13 and PPSV-23) carry a mixture of capsular polysaccharides from Streptococcus pneumoniae. Tetanus vaccines are based on tetanus toxoid combined with aluminum or calcium salts, and meningococcal vaccines are conjugate or recombinant protein vaccines. This contrasts with the emphasis on RNA-based and viral vector vaccines most frequently used for SARS-CoV-2 vaccination.

Based on these differences, (inter-)national guidelines struggle to give consistent recommendations [66, 67, 70-72]. Although some expert statements indicate that the risk of reduced SARS-Cov-2-induced vaccine protection is not proven and no measures should be taken, others recommend performing the vaccination before initiating treatment, interrupting some treatments, or administering the vaccine midcycle in patients receiving biologics. In our opinion, the data on rituximab are sufficient to postpone the vaccination until 6 months after the last dosage of rituximab. For immunosuppressive drugs such as methotrexate and cyclosporine, we recommend stopping treatment for 2 weeks after vaccination for patients aged $>65$ years or for patients with comorbidities that place them at risk for a more severe COVID-19 infection. Special consideration should be given to patients receiving multiple immunosuppressants. However, in our opinion, treatment should only be temporarily stopped in patients with well-controlled skin disorders where the risk of disease flare is low. We believe that biologics (excluding rituximab) can be continued without additional measures, although administering the vaccine midcycle or 2 weeks before vaccination can be considered for TNF $\alpha$ inhibitors if practicable. The value of shared decision making seems underappreciated in most national guidelines.

\section{Conclusion}

Although most guidelines recommend continuing the immunosuppressive/immunomodulating treatments for skin disorders, dermatologists should be aware of their potential to decrease vaccine-induced immunity. This is especially clinically relevant in patients aged $>65$ years or those with comorbidities that place them at risk for a more severe COVID-19 infection.

Acknowledgements The research activities of R. Speeckaert and N. van Geel are supported by the Scientific Research Foundation-Flanders (FWO Senior Clinical Investigator: 18B2721N and 1831512N, respectively) 


\section{Declarations}

Funding The research activities of R. Speeckaert and N. van Geel are supported by the Scientific Research Foundation-Flanders (FWO Senior Clinical Investigator: 18B2721N and 1831512N, respectively).

Conflict of Interest Reinhart Speeckaert, Jo Lambert, Luis Puig, Marijn Speeckaert, Hilde Lapeere, Sofie De Schepper, and Nanja van Geel have no conflicts of interest that are directly relevant to the content of this article.

Availability of data and material Not applicable.

Ethics approval Not applicable.

Consent Not applicable.

Author contributions RS performed the literature search and wrote the draft of the article. All authors critically revised the review. All authors read and approved the final manuscript.

Open Access This article is licensed under a Creative Commons Attribution-NonCommercial 4.0 International License, which permits any non-commercial use, sharing, adaptation, distribution and reproduction in any medium or format, as long as you give appropriate credit to the original author(s) and the source, provide a link to the Creative Commons licence, and indicate if changes were made. The images or other third party material in this article are included in the article's Creative Commons licence, unless indicated otherwise in a credit line to the material. If material is not included in the article's Creative Commons licence and your intended use is not permitted by statutory regulation or exceeds the permitted use, you will need to obtain permission directly from the copyright holder. To view a copy of this licence, visit http://creativecommons.org/licenses/by-nc/4.0/.

\section{References}

1. Poulsen NN, von Brunn A, Hornum M, Blomberg JM. Cyclosporine and COVID-19: risk or favorable? Am J Transplant. 2020;20:2975-82.

2. Polat Ekinci A, Pehlivan G, Gökalp MO. Surveillance of psoriatic patients on biologic treatment during the COVID-19 pandemic: a single-center experience. Dermatol Ther. 2020;2020:e14700.

3. Al-Benna S. Gene expression of angiotensin-converting enzyme 2 receptor in skin and the implications for COVID-19. Adv Skin Wound Care. 2021;34:31-5.

4. Zhou P, Yang X-L, Wang X-G, Hu B, Zhang L, Zhang W, et al. A pneumonia outbreak associated with a new coronavirus of probable bat origin. Nature. 2020;579:270-3.

5. Astuti I, Ysrafil. Severe acute respiratory syndrome coronavirus 2 (SARS-CoV-2): an overview of viral structure and host response. Diabetes Metab Syndr. 2020;14:407-12.

6. Bakhiet M, Taurin S. SARS-CoV-2: targeted managements and vaccine development. Cytokine Growth Factor Rev. 2020;S1359-6101:30227-36.

7. Bloom K, van den Berg F, Arbuthnot P. Self-amplifying RNA vaccines for infectious diseases. Gene Ther. 2020;22:1-13.

8. ISRCTN - ISRCTN17072692: Clinical trial to assess the safety of a coronavirus vaccine in healthy men and women [Internet]. 2021. http://www.isrctn.com/ISRCTN17072692. Accessed 10 Jan 2021.
9. Su F, Patel GB, Hu S, Chen W. Induction of mucosal immunity through systemic immunization: phantom or reality? Hum Vaccin Immunother. 2016;12:1070-9.

10. Speiser DE, Bachmann MF. COVID-19: mechanisms of vaccination and immunity. Vaccines (Basel). 2020;8:404.

11. Sterlin D, Mathian A, Miyara M, Mohr A, Anna F, Claër L, et al. IgA dominates the early neutralizing antibody response to SARSCoV-2. Sci Transl Med. 2020;13:eabd2223.

12. Wang Z, Lorenzi JCC, Muecksch F, Finkin S, Viant C, Gaebler $\mathrm{C}$, et al. Enhanced SARS-CoV-2 neutralization by dimeric IgA. Sci Transl Med. 2020;13:eabf1555.

13. King RG, Silva-Sanchez A, Peel JN, Botta D, Meza-Perez S, Allie $\mathrm{SR}$, et al. Single-dose intranasal administration of AdCOVID elicits systemic and mucosal immunity against SARS-CoV-2 in mice. bioRxiv. Cold Spring Harbor Lab 2020;2020:331348.

14. Park JK, Choi Y, Winthrop KL, Song YW, Lee EB. Optimal time between the last methotrexate administration and seasonal influenza vaccination in rheumatoid arthritis: post hoc analysis of a randomised clinical trial. Ann Rheum Dis. 2019;78:1283-4.

15. Park JK, Lee YJ, Shin K, Ha Y-J, Lee EY, Song YW, et al. Impact of temporary methotrexate discontinuation for 2 weeks on immunogenicity of seasonal influenza vaccination in patients with rheumatoid arthritis: a randomised clinical trial. Ann Rheum Dis. 2018;77:898-904.

16. Palestine AG, Roberge F, Charous BL, Lane HC, Fauci AS, Nussenblatt RB. The effect of cyclosporine on immunization with tetanus and keyhole limpet hemocyanin (KLH) in humans. J Clin Immunol. 1985;5:115-21.

17. Versluis DJ, Beyer WE, Masurel N, Wenting GJ, Weimar W. Impairment of the immune response to influenza vaccination in renal transplant recipients by cyclosporine, but not azathioprine. Transplantation. 1986;42:376-9.

18. Karbasi-Afshar R, Izadi M, Fazel M, Khedmat H. Response of transplant recipients to influenza vaccination based on type of immunosuppression: a meta-analysis. Saudi J Kidney Dis Transpl. 2015;26:877-83.

19. Mazzone PJ, Mossad SB, Mawhorter SD, Mehta AC, Schilz RJ, Maurer JR. The humoral immune response to influenza vaccination in lung transplant patients. Eur Respir J. 2001;18:971-6.

20. Oesterreich S, Lindemann M, Goldblatt D, Horn PA, Wilde B, Witzke O. Humoral response to a 13-valent pneumococcal conjugate vaccine in kidney transplant recipients. Vaccine. 2020;38:3339-50.

21. Papp KA, Haraoui B, Kumar D, Marshall JK, Bissonnette R, Bitton A, et al. Vaccination guidelines for patients with immunemediated disorders on immunosuppressive therapies. J Cutan Med Surg. 2019;23:50-74.

22. Inoue S, Shibata Y, Takabatake N, Igarashi A, Abe S, Kubota I. Influence of corticosteroid therapy on the serum antibody response to influenza vaccine in elderly patients with chronic pulmonary diseases. EXCLI J. 2013;12:760-5.

23. de Roux A, Marx A, Burkhardt O, Schweiger B, Borkowski A, Banzhoff A, et al. Impact of corticosteroids on the immune response to a MF59-adjuvanted influenza vaccine in elderly COPD-patients. Vaccine. 2006;24:1537-42.

24. Park CL, Frank AL, Sullivan M, Jindal P, Baxter BD. Influenza vaccination of children during acute asthma exacerbation and concurrent prednisone therapy. Pediatrics. 1996;98:196-200.

25. Ulinski T, Leroy S, Dubrel M, Danon S, Bensman A. High serological response to pneumococcal vaccine in nephrotic children at disease onset on high-dose prednisone. Pediatr Nephrol. 2008;23:1107-13.

26. Hanania NA, Sockrider M, Castro M, Holbrook JT, Tonascia J, Wise R, et al. Immune response to influenza vaccination in children and adults with asthma: effect of corticosteroid therapy. J Allergy Clin Immunol. 2004;113:717-24. 
27. Russell AF, Parrino J, Fisher CL, Spieler W, Stek JE, Coll KE, et al. Safety, tolerability, and immunogenicity of zoster vaccine in subjects on chronic/maintenance corticosteroids. Vaccine. 2015;33:3129-34.

28. von Hehn C, Howard J, Liu S, Meka V, Pultz J, Mehta D, et al. Immune response to vaccines is maintained in patients treated with dimethyl fumarate. Neurol Neuroimmunol Neuroinflamm. 2018;5:e409.

29. Schafer PH, Parton A, Capone L, Cedzik D, Brady H, Evans JF, et al. Apremilast is a selective PDE4 inhibitor with regulatory effects on innate immunity. Cell Signal. 2014;26:2016-29.

30. Andrade P, Santos-Antunes J, Rodrigues S, Lopes S, Macedo G. Treatment with infliximab or azathioprine negatively impact the efficacy of hepatitis B vaccine in inflammatory bowel disease patients. J Gastroenterol Hepatol. 2015;30:1591-5.

31. Dotan I, Werner L, Vigodman S, Agarwal S, Pfeffer J, Horowitz $\mathrm{N}$, et al. Normal response to vaccines in inflammatory bowel disease patients treated with thiopurines. Inflamm Bowel Dis. 2021;18:261-8.

32. Fiorino G, Peyrin-Biroulet L, Naccarato P, Szabò H, Sociale OR, Vetrano S, et al. Effects of immunosuppression on immune response to pneumococcal vaccine in inflammatory bowel disease: a prospective study. Inflamm Bowel Dis. 2012;18:1042-7.

33. Keshtkar-Jahromi M, Argani H, Rahnavardi M, Mirchi E, Atabak $\mathrm{S}$, Tara SA, et al. Antibody response to influenza immunization in kidney transplant recipients receiving either azathioprine or mycophenolate: a controlled trial. Am J Nephrol. 2008;28:654-60.

34. Rizzi M, Lorenzetti R, Fischer K, Staniek J, Janowska I, Troilo A, et al. Impact of tofacitinib treatment on human B-cells in vitro and in vivo. J Autoimmun. 2017;77:55-66.

35. Winthrop KL, Korman N, Abramovits W, Rottinghaus ST, Tan $\mathrm{H}$, Gardner A, et al. T-cell-mediated immune response to pneumococcal conjugate vaccine (PCV-13) and tetanus toxoid vaccine in patients with moderate-to-severe psoriasis during tofacitinib treatment. J Am Acad Dermatol. 2018;78:1149-1155.e1.

36. Winthrop KL, Bingham CO, Komocsar WJ, Bradley J, Issa M, Klar R, et al. Evaluation of pneumococcal and tetanus vaccine responses in patients with rheumatoid arthritis receiving baricitinib: results from a long-term extension trial substudy. Arthritis Res Ther. 2019;21:102.

37. Evaluation of Response to Pneumococcal Vaccination in Patients with Rheumatoid Arthritis Receiving Upadacitinib: Results from a Phase 2 Open-Label Extension Study [Internet]. ACR Meeting Abstracts. 2021. https://acrabstracts.org/abstract/evaluation-ofresponse-to-pneumococcal-vaccination-in-patients-with-rheum atoid-arthritis-receiving-upadacitinib-results-from-a-phase-2open-label-extension-study/. Accessed 25 Apr 2021.

38. França ILA, Ribeiro ACM, Aikawa NE, Saad CGS, Moraes JCB, Goldstein-Schainberg C, et al. TNF blockers show distinct patterns of immune response to the pandemic influenza $\mathrm{A}$ H1N1 vaccine in inflammatory arthritis patients. Rheumatology. 2012;51:2091-8

39. Kapetanovic MC, Saxne T, Nilsson J-Å, Geborek P. Influenza vaccination as model for testing immune modulation induced by antiTNF and methotrexate therapy in rheumatoid arthritis patients. Rheumatology. 2007;46:608-11.

40. Kapetanovic MC, Saxne T, Sjöholm A, Truedsson L, Jönsson G, Geborek P. Influence of methotrexate, TNF blockers and prednisolone on antibody responses to pneumococcal polysaccharide vaccine in patients with rheumatoid arthritis. Rheumatology. 2006;45:106-11.

41. Strand V, Balsa A, Al-Saleh J, Barile-Fabris L, Horiuchi T, Takeuchi T, et al. Immunogenicity of biologics in chronic inflammatory diseases: a systematic review. BioDrugs. 2017;31:299-316.
42. Furer V, Zisman D, Kaufman I, Arad U, Berman M, SarbagilMaman $\mathrm{H}$, et al. Immunogenicity and safety of vaccination against seasonal influenza vaccine in patients with psoriatic arthritis treated with secukinumab. Vaccine. 2020;38:847-51.

43. Richi P, Martín MD, de Ory F, Gutiérrez-Larraya R, Casas I, Jiménez-Díaz AM, et al. Secukinumab does not impair the immunogenic response to the influenza vaccine in patients. RMD Open. 2019;5:e01018.

44. Chioato A, Noseda E, Stevens M, Gaitatzis N, Kleinschmidt A, Picaud H. Treatment with the interleukin-17A-blocking antibody secukinumab does not interfere with the efficacy of influenza and meningococcal vaccinations in healthy subjects: results of an open-label, parallel-group, randomized single-center study. Clin Vaccine Immunol. 2012;19:1597-602.

45. Gomez EV, Bishop JL, Jackson K, Muram TM, Phillips D. Response to tetanus and pneumococcal vaccination following administration of ixekizumab in healthy participants. BioDrugs. 2017;31:545-54.

46. FDA Approves Taltz [Internet]. 2020. https://www.accp1.org/ ACCP1/5Publications_and_News/FDA_Approves_Taltz.aspx. Accessed 31 Dec 2020.

47. Beck KM, Koo J. Brodalumab for the treatment of plaque psoriasis: up-to-date. Expert Opin Biol Ther. 2019;19:287-92.

48. Frieder J, Kivelevitch D, Menter A. Secukinumab: a review of the anti-IL-17A biologic for the treatment of psoriasis. Ther Adv Chronic Dis. 2018;9:5-21.

49. Oliveira DG, Faria R, Torres T. An overview of bimekizumab for the treatment of psoriatic arthritis: the evidence so far. Drug Des Devel Ther. 2021;15:1045-53.

50. Doornekamp L, Goetgebuer RL, Schmitz KS, Goeijenbier M, van der Woude CJ, Fouchier R, et al. High immunogenicity to influenza vaccination in Crohn's disease patients treated with ustekinumab. Vaccines (Basel). 2020;8:455.

51. Brodmerkel C, Wadman E, Langley RG, Papp KAA, Bourcier M, Poulin Y, et al. Immune response to pneumococcus and tetanus toxoid in patients with moderate-to-severe psoriasis following long-term ustekinumab use. J Drugs Dermatol. 2013;12:1122-9.

52. Frampton JE. Tildrakizumab: a review in moderate-to-severe plaque psoriasis. Am J Clin Dermatol. 2019;20:295-306.

53. Pang Y, Khatri A, Suleiman AA, Othman AA. Clinical pharmacokinetics and pharmacodynamics of risankizumab in psoriasis patients. Clin Pharmacokinet. 2020;59:311-26.

54. Zhuang Y, Calderon C, Marciniak SJ, Bouman-Thio E, Szapary $\mathrm{P}$, Yang T-Y, et al. First-in-human study to assess guselkumab (anti-IL-23 mAb) pharmacokinetics/safety in healthy subjects and patients with moderate-to-severe psoriasis. Eur J Clin Pharmacol. 2016;72:1303-10.

55. Scherl EJ, Kumar S, Warren RU. Review of the safety and efficacy of ustekinumab. Therap Adv Gastroenterol. 2010;3:321-8.

56. Blauvelt A, Simpson EL, Tyring SK, Purcell LA, Shumel B, Petro CD, et al. Dupilumab does not affect correlates of vaccineinduced immunity: a randomized, placebo-controlled trial in adults with moderate-to-severe atopic dermatitis. J Am Acad Dermatol. 2019;80:158-167.e1.

57. Ranasinghe C, Trivedi S, Wijesundara DK, Jackson RJ. IL-4 and IL-13 receptors: Roles in immunity and powerful vaccine adjuvants. Cytokine Growth Factor Rev. 2014;25:437-42.

58. Baker D, Roberts CAK, Pryce G, Kang AS, Marta M, Reyes $\mathrm{S}$, et al. COVID-19 vaccine-readiness for anti-CD20-depleting therapy in autoimmune diseases. Clin Exp Immunol. 2020;202:149-61.

59. van Assen S, Holvast A, Telgt DSC, Benne CA, de Haan A, Westra J, et al. Patients with humoral primary immunodeficiency do not develop protective anti-influenza antibody titers 
after vaccination with trivalent subunit influenza vaccine. Clin Immunol. 2010;136:228-35.

60. Parrino J, McNeil SA, Lawrence SJ, Kimby E, Pagnoni MF, Stek JE, et al. Safety and immunogenicity of inactivated varicella-zoster virus vaccine in adults with hematologic malignancies receiving treatment with anti-CD20 monoclonal antibodies. Vaccine. 2017;35:1764-9.

61. Sahin U, Muik A, Derhovanessian E, Vogler I, Kranz LM, Vormehr M, et al. COVID-19 vaccine BNT162b1 elicits human antibody and TH1 T cell responses. Nature. 2020;586:594-9.

62. Peng Y, Mentzer AJ, Liu G, Yao X, Yin Z, Dong D, et al. Broad and strong memory CD4+ and CD8+ T cells induced by SARSCoV-2 in UK convalescent individuals following COVID-19. Nat Immunol. 2020;21:1336-45.

63. Christensen D, Mortensen R, Rosenkrands I, Dietrich J, Andersen P. Vaccine-induced Th17 cells are established as resident memory cells in the lung and promote local IgA responses. Mucosal Immunol. 2017;10:260-70.

64. Gabay C, Bel M, Combescure C, Ribi C, Meier S, Posfay-Barbe $\mathrm{K}$, et al. Impact of synthetic and biologic disease-modifying antirheumatic drugs on antibody responses to the AS03-adjuvanted pandemic influenza vaccine: a prospective, open-label, parallelcohort, single-center study. Arthritis Rheum. 2011;63:1486-96.

65. Tanrı̈̈ver MD, Akar S, Türkçapar N, Karadağ Ö, Ertenli İ, Kiraz $\mathrm{S}$. Vaccination recommendations for adult patients with rheumatic diseases. Eur J Rheumatol. 2016;3:29-35.

66. Gelfand JM, Armstrong AW, Bell S, Anesi GL, Blauvelt A, Calabrese C, et al. National Psoriasis Foundation COVID-19 Task Force guidance for management of psoriatic disease during the pandemic: Version 2-Advances in psoriatic disease management,
COVID-19 vaccines, and COVID-19 treatments. J Am Acad Dermatol. 2021;84:1254-68.

67. GRPSO : Conseils aux patients atteints de Psoriasis concernant la vaccination contre la COVID-19 (SARS-Cov-2) [Internet]. 2021. https://grpso.org/grpso-news.php?id=67. Accessed 25 Apr 2021.

68. Hallare J, Gerriets V. Half Life. StatPearls [Internet]. Treasure Island (FL): StatPearls Publishing. 2020. http://www.ncbi.nlm. nih.gov/books/NBK554498/. Accessed 1 Jan 2021.

69. Mohme S, Schmalzing M, Müller CSL, Vogt T, Goebeler M, Stoevesandt J. Immunizations in immunocompromised patients: a guide for dermatologists. J Deutschen Dermatologischen Gesellschaft. 2020;18:699-723.

70. Impfungen gegen SARS-CoV-2: Empfehlungen der Deutschen Dermatologischen Gesellschaft (DDG) [Internet]. 2021. https:// derma.de/fortbildung/kalender/uebersicht/detail/news/empfe hlung-fuer-impfung-gegen-sars-cov-2-der-deutschen-dermatolog ischengesellschaft/?tx_news_pi $1 \% 5 \mathrm{Bcontroller} \% 5 \mathrm{D}=\mathrm{News} \&$ tx_news_pi $1 \% 5$ Baction $\% 5 \mathrm{D}=$ detail\&cHash $=$ dd659c2b7d02a01 df7eacbc0bd65a21a. Accessed 2 May 2021.

71. Health AGD of. ATAGI - Provider guide to COVID-19 vaccination of people with immunocompromise [Internet]. Australian Government Department of Health. Australian Government Department of Health. 2021. https://www.health.gov.au/resou rces/publications/atagi-provider-guide-to-covid-19-vaccinationof-people-with-immunocompromise. Accessed 2 May 2021.

72. Using COVID-19 vaccines in patient taking immunosuppressive medicines [Internet]. SPS—Specialist Pharmacy Service. 2021. https://www.sps.nhs.uk/articles/using-covid-19-vaccines-in-patie nt-taking-immunosuppressive-medicines/. Accessed 2 May 2021. 